Titulo do Trabalho

\title{
TECNOLOGIA ALTERNATIVA PARA PROTEÇÃO CONTRA CORROSÃO DE LIGAS DE ALUMÍNIO
}

Nome do Autor Principal

Herbert Duchatsch Johansen

Nome do Orientador

Artur de Jesus Motheo

Instituição

Universidade de São Paulo - Instituto de Química de São Carlos

Instituição de Fomento

Conselho Nacional de Pesquisa e Desenvolvimento - CNPq

E-mail de Contato

hdjohansen@gmail.com

Palavras-Chave

Ligas de alumínio. Proteção contra a corrosão. Camadas de conversão de cério.

\section{INTRODUÇÃO}

O alumínio é certamente o segundo metal mais importante com relação a usos práticos e sua grande abundância o faz um substituto natural do aço. $O$ alumínio é corroído tanto em meio ácido como em meio alcalino em um intervalo de potencial substancial, mas, para o intervalo de $\mathrm{pH}$ entre 4 e 9 , correspondente ao intervalo comum de atividade, ocorre a formação de uma camada passiva altamente protetora (JOHANSEN, BÜRGER \& MOTHEO, 2010). Em situações de uso externo e após vários anos, pode ser observada a ocorrência de corrosão por pites. Em contato permanente com água, este tipo de corrosão é bem mais severo, sendo que as quantidades de oxigênio dissolvido e de cloreto presentes no meio determinam o grau de ataque ao 
metal. Da mesma forma que para o ferro e aços, outros tipos de corrosão podem ocorrer, tais como corrosão galvânica e corrosão sob tensão.

Atentos a problemática de corrosão do alumínio e suas ligas, as primeiras investigações realizadas com camadas de conversão de cério, como método para proteção contra a corrosão de ligas de alumínio, foram realizadas pela Divisão de Materiais dos Laboratórios de Pesquisas Aeronáuticas da Austrália em meados dos anos 80 do século XX (HINTON, ARNOT \& RYAN, 1984; HINTON, ARNOT \& RYAN, 1986). Nestes trabalhos foi verificado que a imersão da liga de alumínio AA7075 em soluções contendo pequenas quantidades de $\mathrm{CeCl}_{3}$ provocava a formação de uma camada protetora sobre a superfície, que conseguia diminuir a velocidade de corrosão da liga (ARNOT, HINTON \& RYAN, 1987). Alguns anos depois, os mesmos autores verificaram que um aumento na eficiência da formação da camada podia ser obtido pela adição de pequenas quantidades de $\mathrm{H}_{2} \mathrm{O}_{2}$ ao banho de conversão.

A partir de alguns desses trabalhos desenvolveu-se crescente interesse no mundo científico com relação à melhoria das características das camadas de conversão à base de cério, uma vez que as mesmas passaram a ser encaradas como substitutas em potencial para as camadas de conversão de cromo. Tratamentos à base de cromo são utilizados atualmente na indústria aeroespacial, tanto civil como militar, entretanto as características carcinogênicas e poluentes do cromo hexavalente tornaram necessária sua substituição no mais curto espaço de tempo.

\section{OBJETIVO GERAL}

As ligas de alumínio vêm sendo amplamente utilizadas em indústrias aeronáuticas e automotivas por suas propriedades mecânicas superiores às do alumínio puro. Contudo, como as propriedades de corrosão dessas ligas variam, há a necessidade de estudos de diferentes métodos de proteção contra a corrosão. Os revestimentos de proteção usuais, baseados em cromo, têm se mostrado prejudiciais ao meio ambiente e à saúde humana. Por outro lado, os revestimentos protetores à base de cério, mais ecologicamente corretos e salubres, emergem como alternativa promissora para a inibição de processos corrosivos e o aumento da vida útil destes materiais. 


\section{OBJETIVOS ESPECÍFICOS}

Este trabalho teve como objetivo investigar a aplicação de camadas de conversão de cério, utilizando $\mathrm{Ce}\left(\mathrm{NO}_{3}\right)_{3} \cdot 6 \mathrm{H}_{2} \mathrm{O}$, sobre a liga de alumínio AA6061 e estudar os efeitos protetores contra a corrosão dessas camadas.

\section{METODOLOGIA}

\section{Preparação das amostras}

Amostras da liga de alumínio AA6061 precedentes da Alcoa Alumínio SA foram cortadas em chapas ( $20 \times 25 \times 5 \mathrm{~mm}$ ) e em discos ( $\varnothing=20 \mathrm{~mm}$ ). Após usinagem, as amostras foram desengraxadas com acetona utilizando ultrassom. As amostras das diferentes ligas, após polimento mecânico com lixas (de 100 a 1200 mesh, a granulometria), foram imersas em etanol, lavadas com água e secas ao ar quente. As amostras precedidas apenas desta etapa foram denominadas como AA6061.

\section{Preparação de camadas de conversão de cério}

As deposições das camadas de conversão de cério foram realizadas pelo método "electroless", o qual consiste na deposição da camada de conversão de cério sem aplicação de corrente ou potencial externo.

As amostras foram nomeadas como $\mathrm{AA} 6061_{\mathrm{ce}} \mathrm{e}$ as condições utilizadas foram:

- Pré-tratamento: 5 min em NaOH (Synth), $50 \mathrm{~g} \mathrm{~L}^{-1}$, a $25 \pm 2 \stackrel{\circ}{\circ}$;

- Concentração de $\mathrm{Ce}\left(\mathrm{NO}_{3}\right)_{3} 6 \mathrm{H}_{2} \mathrm{O}$ (Aldrich): $5 \times 10^{-3} \mathrm{~mol} \mathrm{~L}^{-1}$;

- Tempo de imersão: 10 min;

- $\mathrm{pH}: 4,0$, ajustado com $\mathrm{HNO}_{3}$ (Mallinckrodt) $5 \%$ e $\mathrm{NaOH}$ (Synth) 5\%;

- Temperatura: $25 \pm 2 \stackrel{\circ}{ } \mathrm{C}$;

- Quantidade de $\mathrm{H}_{2} \mathrm{O}_{2}$ (Synth) $30 \%$ adicionada: $10 \mathrm{~mL} \mathrm{~L}^{-1}$.

\section{Ensaios eletroquímicos}

Todas as amostras deste estudo foram caracterizadas pela técnica de polarização potenciodinâmica. Para tanto, estes ensaios de corrosão foram realizados em meio 
aquoso de $\mathrm{NaCl} 3,5 \%$, naturalmente aerado, a $25 \pm 2{ }^{\circ} \mathrm{C} \mathrm{e} \mathrm{v}=1 \mathrm{mV} \mathrm{s}^{-1}$. Para estes estudos foram utilizados uma célula eletroquímica de compartimento único, um contraeletrodo de chapa de platina ( $20 \times 20 \mathrm{~mm}$ ) e um eletrodo de calomelanos saturado (ECS), como referência, sendo um Potenciostato/Galvanostato (EG\&G/PAR, 273A), acoplado ao software M352/252, empregado na realização dos ensaios.

Nestes experimentos, dados de potencial de corrosão ( $\left.\mathrm{E}_{\text {corr }}\right)$, potencial de pite $\left(E_{\text {pite }}\right)$, densidade de corrente de corrosão (j $\left.j_{\text {corr }}\right)$ e taxa de corrosão são obtidos.

\section{RESULTADOS}

As condições descritas e adotadas neste estudo referem-se às condições otimizadas, obtidas de diversos estudos e testes realizados para a obtenção da melhor condição de banho para a deposição das camadas de cério sobre esta liga de alumínio. Estas variáveis também são objetos de diferentes estudos na literatura (JOHANSEN \& MOTHEO, 2010-a; JOHANSEN \& MOTHEO, 2010-b; PALOMINO et al., 2003), as quais confirmam a forte influência dos parâmetros sobre as características das camadas de cério sobre as ligas de alumínio e seus efeitos sobre a proteção contra a corrosão.

As camadas de conversão de cério obtidas são formadas sobre a liga de alumínio AA6061 na composição investigada, não de maneira espessa sobre a superfície, diferentemente de outros métodos (SALAZAR-BANDA et al., 2009) ou utilizando outros sais de cério (PALOMINO et al., 2003). Desta maneira, a economia da quantidade de cério utilizada e a dispersão do depósito sobre toda a superfície foi alcançada. O processo completo de deposição da camada de conversão de cério origina uma superfície rugosa que propicia eficiente proteção contra a corrosão quando em comparação à liga sem qualquer tratamento.

Os parâmetros de corrosão encontrados foram: para a liga AA6061 $\left(E_{c o r r}=-843\right.$ $\mathrm{mV}, \mathrm{E}_{\text {pite }}=-667 \mathrm{mV}, \mathrm{j}_{\text {corr }}=0,685 \mu \mathrm{A} \mathrm{cm} \mathrm{cm}^{-2}$ e taxa de corrosão $=0,291 \mathrm{~mm} \mathrm{ano}^{-1}$ ) e para a liga $A A 6061_{\mathrm{Ce}}\left(E_{\text {corr }}=-685 \mathrm{mV}, E_{\text {pite }}=-535 \mathrm{mV}, j_{\text {corr }}=0,116 \mu \mathrm{A} \mathrm{cm}{ }^{-2}\right.$ e taxa de corrosão $=$ $0,049 \mathrm{~mm} \mathrm{ano}^{-1}$ ). Pode ser verificado que estas camadas de conversão conseguem suprimir os processos corrosivos que imperam sobre a liga de alumínio AA6061 em meios corrosivos, configurando a este recobrimento propriedades anticorrosivas. 
Quando óxidos hidratados de cério são formados sobre a superfície da liga em adição ao óxido de alumínio, uma barreira ao fluxo de elétrons pode ser criada. Então, a velocidade da reação de redução do oxigênio pode ser reduzida e a corrosão inibida. Portanto os ramos catódicos e anódicos das curvas de polarização apresentam menores valores de densidade de corrente, quando comparados às ligas não tratadas.

\section{CONSIDERAÇÕES FINAIS}

Neste estudo, revestimentos baseados em cério de alta eficiência contra a corrosão foram produzidos e aplicados sobre a liga de alumínio AA6061. Foi demonstrado que os revestimentos de óxido de cério preparados neste estudo podem atuar como uma barreira ativa contra a corrosão e ajudaram a proteger o substrato metálico do efeito corrosivo de um eletrólito. Esta nova abordagem abre a oportunidade para que revestimentos protetores deste tipo passem a ser vistos como tecnologias alternativas para proteção contra a corrosão do alumínio e de suas ligas, bem como de outros substratos metálicos susceptíveis à corrosão.

\section{REFERÊNCIAS}

ARNOT, D. R.; HINTON, B. R. W.; RYAN, N. E. Cationic film-forming inhibitors for the corrosion protection of AA $\mathbf{7 0 7 5}$ aluminum alloy in chloride solutions. Materials Performance, v. 26, p. 42-47, 1987.

HINTON, B. R. W.; ARNOT, D. R.; RYAN, N. E. Cerium conversion coatings for the corrosion protection of aluminum. Metals Forum, v. 9, n. 3, p.162-173, 1986.

HINTON, B. R. W.; ARNOT, D. R.; RYAN, N. E. The inhibition of aluminum alloy corrosion by cerous cations. Metals Forum, v.7, n. 4, p. 211-217, 1984.

JOHANSEN, H. D.; BÜRGER, B. L.; MOTHEO, A. J. Avaliação do efeito anticorrosivo de camadas de conversão de cério associado a polímeros condutores em ensaios acelerados de corrosão. 33. ${ }^{a}$ RA da Sociedade Brasileira de Química. Águas de Lindóia, SP, Brasil, 2010. 


\section{FÓRUM AMBIENTAL DA ALTA PAULISTA}

Volume VI - Ano 2010

JOHANSEN, H. D.; MOTHEO, A. J. Cerium conversion coatings for corrosion protection of aluminum alloys: the influence of bath parameters. IX Brazilian Materials Research Society Meeting, Ouro Preto, MG, Brazil, 2010-a.

JOHANSEN, H. D.; MOTHEO, A. J. Proteção anticorrosiva de ligas de alumínio por camadas de conversão de cério associadas com polímeros condutores. XIX Congresso de la Sociedad Iberoamericana de Electroquímica y XXXI Reunión del Grupo de Electroquímica de la Real Sociedad Española de Química. Alcalá de Henares, Madrid, España, 2010-b.

PALOMINO, L. E. M.; CASTRO, J. F.; AOKI, I. V.; MELO, H. G. Microstructural and electrochemical characterization of environmentally friendly conversion layers on aluminum alloys. Journal of the Brazilian Chemical Society, v. 14, p. 651-659, 2003.

SALAZAR-BANDA, G. R.; MORAES, S. R.; MOTHEO, A. J.; MACHADO, S. A. S. Anticorrosive cerium-based coatings prepared by the sol-gel method. Journal of SolGel Science and Technology, v. 52, p. 415-423, 2009. 